\title{
A castanheira: história natural e importância socioeconômica
}

\author{
Rafael de Paiva Salomão \\ Museu Paraense Emílio Goeldi/MCTI
}

Bertholletia excelsa Bonpl., espécie popularmente denominada de castanheira, castanheira-do-brasil, castanheira-do-pará, castanheira-do-maranhão, castanheira-da-amazônia, Brazil nuts ou Para nuts, para os anglo-americanos, e noix du Brésil ou noix de Para, para os franceses, produz amêndoas que são conhecidas e muito apreciadas na Europa desde 1633.

De acordo com o pesquisador José Edmar Urano de Carvalho, da Empresa Brasileira de Pesquisa Agropecuária (EMBRAPA) Amazônia Oriental:

\begin{abstract}
a castanheira-do-brasil é espécie de uso múltiplo, nativa da Amazônia e amplamente explorada ao longo dos tempos em sistema extrativista, tanto por suas sementes comestíveis como por sua madeira, utilizada principalmente na construção de casas. No passado, as fibras retiradas da entrecasca também foram produtos importantes para a calafetagem de embarcações. O primeiro relato sobre essa espécie foi efetuado por Frei Cristóvão de Lisboa, no século XVII, quando enfatizou que o consumo excessivo de suas sementes implicava queda dos cabelos. À luz do conhecimento atual, a queda de cabelos é um dos sintomas da selenose, ou seja, da toxicidade do consumo de selênio em níveis muito acima do requerido pelo organismo humano. Esse elemento químico ocorre em níveis bastante elevados nas amêndoas de castanha-do-brasil. O que era conhecido pelos aborígenes do Pará como anhaúba foi, inicialmente, denominado pelos europeus como castanha-do-maranhão. Posteriormente, o colonizador português a denominou de castanha-do-brasil e, quando o estado do Pará tornou-se o seu maior produtor e exportador, passou a ser designada como castanha-do-pará, nome ainda bastante utilizado na Amazônia brasileira. $\bigcirc$ nome castanha-do-brasil, como atualmente é conhecida em todo o mundo, foi adotado oficialmente pelo governo brasileiro na década de 1950, com vista ao comércio internacional. Essa denominação vem, nos últimos anos, sendo contestada por organizações não governamentais e por outros países produtores, que têm, sem sucesso, proposto o nome de castanha-da-amazônia (J. E. U. Carvalho, comunicação pessoal, 19 de junho de 2013).
\end{abstract}

A castanheira-do-brasil foi descrita, em 1808, pelo botânico francês Aimé Jacques Alexandre Goujaud Bonpland, com o nome de Bertholletia excelsa. Durante muitos anos a espécie foi erroneamente designada como Bertholletia excelsa H. \& B., muito certamente devido ao fato de a obra na qual foi descrita ser composta por dois volumes ("Voyage de Humboldt et Bonpland. sixième partie, Botanique, Plantes Équinoxiales", F. Schoell, Paris, [1805-] 1808-09 [-1817], 2 v.). No entanto, a espécie foi descrita no volume 1, por Aimee Jacques Alexandre Goujaud Bonpland, que também era o único autor daquele volume ("Plantes Équinoxiales", 1: 122-127, 1808). Na referida obra do descritor da espécie, encontra-se uma bela prancha (n. 36) referente a B. excelsa, a qual é apresentada na Figura 1.

○ome genérico, Bertholletia, é uma homenagem ao médico, químico e fisiologista francês Claude Louis Berthollet, enquanto o epíteto específico, excelsa, significa majestosa, alta, em alusão ao porte da planta, cuja altura pode atingir $60 \mathrm{~m}$ e diâmetro até pouco mais de $5 \mathrm{~m}$. $\bigcirc$ gênero Bertholletia é monotipo, ou seja, tem como único representante a espécie $B$. excelsa. $O$ botânico inglês John Miers, em 1874, descreveu incorretamente uma espécie com o nome de Bertholletia nobilis Miers, que, na verdade, é a própria B. excelsa.

Árvore bela e majestosa, é uma das mais nobres da megadiversa e opulenta flora do bioma Amazônia. A castanheira é uma espécie excepcional, que apresenta um concurso de circunstâncias poucas vezes reunido pela Natureza em uma só planta: alta longevidade, aliada a uma grande produção de castanha comestível, muito apreciada nos continentes europeu, asiático e americanos, além de possuir um tronco quase perfeitamente cilíndrico.

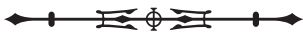




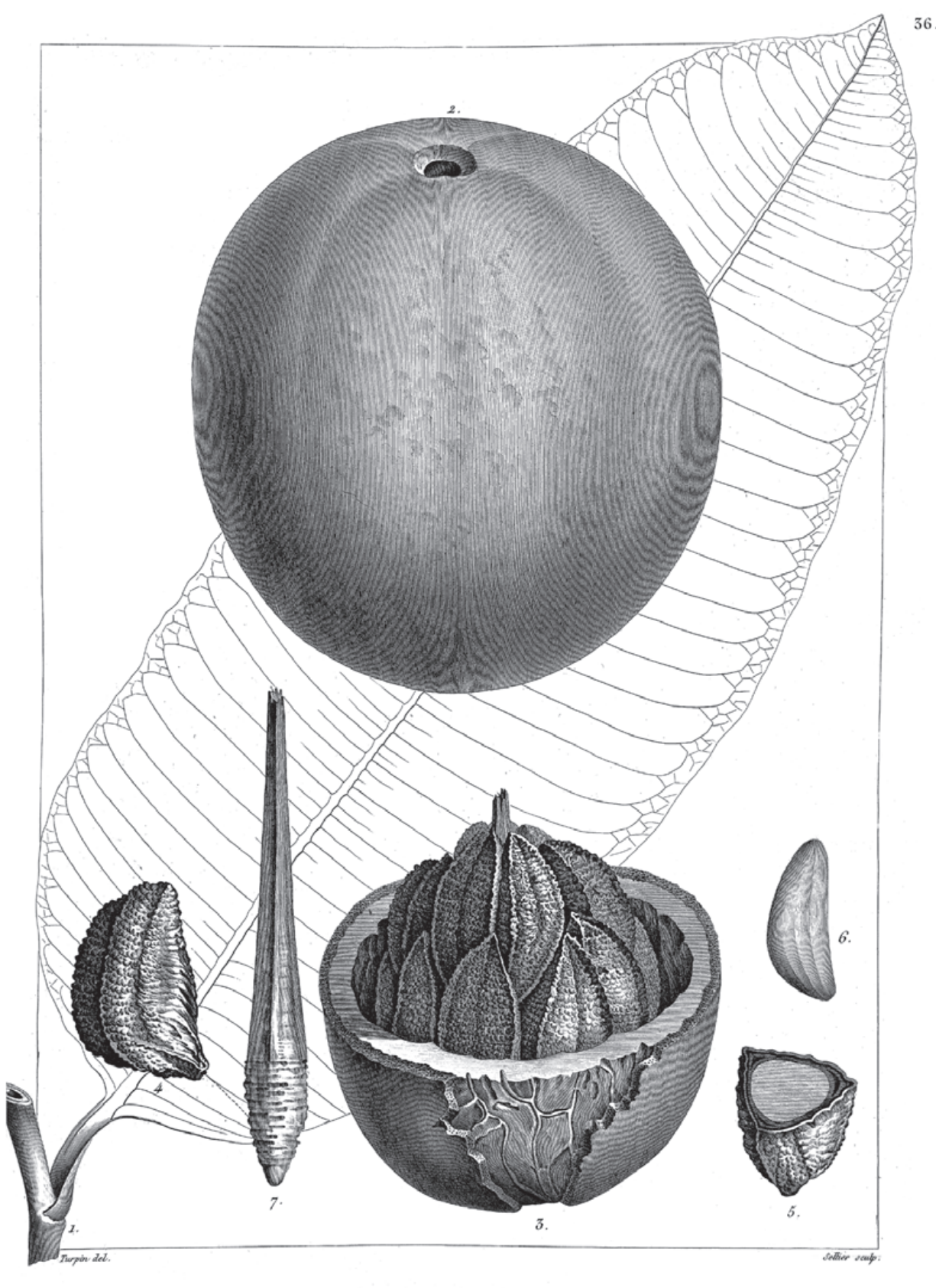

BERTHOLLETIA excelsa.

Figura 1. Reprodução da prancha 36 referente à descrição de Bertholletia excelsa por Aimé Jacques Alexandre Bonpland, em 1808, e apresentada na obra "Bertholletia excelsa Bonpl. in F. W. H. A. von Humboldt \& A. J. A. Bonpland, Pl. Aequinoct." (1: 122, 1808). Legendas: (1) uma folha inteira; (2) fruto inteiro; (3) fruto cortado ao meio para mostrar o arranjo das sementes; (4) semente inteira; (5) semente cortada transversalmente mostrando os três nós que são correspondentes aos ângulos; (6) uma amêndoa; (7) coluna do centro do fruto onde se inserem as sementes.

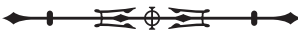


Historicamente, o valor econômico de seus frutos sempre foi muito relevante no contexto regional. A prosperidade do Pará e do Amazonas, que havia repousado longo tempo sobre o ciclo da borracha, só pôde se manter quando sobreveio a baixa de preço deste artigo, graças à castanha, que os poupou de maiores contratempos, passando a ocupar o primeiro lugar, como valor e como renda, nas exportações de ambos os estados.

Todavia, as políticas públicas sempre influenciaram poderosamente os rumos da Amazônia. Quem imaginaria que a criação dos incentivos fiscais, em 1966, iria provocar os grandes desmatamentos na Amazônia? Como consequência, entre tantas outras, favoreceu a virtual destruição de praticamente todas as árvores de castanha do 'polígono dos castanhais', na região de Marabá, estado do Pará. A partir das últimas quatro décadas do século passado, a Amazônia - com seu grande espaço econômico e potencial de riquezas minerais, energéticas, além de sua megabiodiversidade, incluindo os serviços ecossistêmicos - passou a influir mais firmemente nos rumos de seu futuro.

Atualmente, a castanheira encontra-se presente nas listas de espécies ameaçadas de extinção do Ministério do Meio Ambiente (MMA), publicadas em 2008, e do estado do Pará. A domesticação da espécie em plantios homogêneos vem sendo feita sobretudo no estado do Amazonas. Centenas de estudos da espécie já foram concluídos, sem que, no entanto, se esgote o assunto, como muito bem apresentado neste dossiê, com destaque para as recomendações do artigo de Evert Thomas e colaboradores.

Considerando a imensa vastidão das florestas primárias e antropizadas na Amazônia e a importância da castanheira neste bioma, torna-se urgente avançar no entendimento ecológico, econômico e social da espécie, procurando identificar as lacunas de pesquisas existentes. $\bigcirc$ reconhecimento do papel da castanheira na estrutura da floresta e de seu potencial como suporte para o desenvolvimento socioeconômico e ecossistêmico passa, necessariamente, pela intensificação dos estudos sobre tão importante espécie, quer em seu ambiente natural, nas florestas antropizadas, nas áreas de restauração, nos sistemas agroflorestais ou nos plantios homogêneos.

Este número especial do Boletim do Museu Paraense Emílio Goeldi. Ciências Naturais, intitulado "A castanheira: história natural e importância socioeconômica", é uma contribuição do Museu Paraense Emílio Goeldi com o objetivo de difundir resultados de estudos atuais sobre a espécie e apontar a necessidade de outras pesquisas para a plena compreensão do seu papel no contexto do Homem e da Natureza. Em seu conjunto, este número apresenta uma síntese de muitos anos de pesquisas e experiências práticas de pesquisadores brasileiros e de outros países.

O primeiro artigo deste número é o excelente estudo da equipe liderada por Evert Thomas, que modelou a distribuição potencial da castanha-do-brasil durante diferentes passados climáticos, assim como durante vários períodos futuros. $\bigcirc$ estudo demonstra que as projeções do potencial de distribuição para diferentes cenários climáticos vindouros predizem um futuro positivo para a castanha-do-brasil. Se a espécie tem sido capaz de sobreviver a períodos passados de resfriamento/aquecimento e de secagem/umedecimento, deve, certamente, ter capacidade de persistir ao longo de futuras mudanças climáticas, particularmente quando são criadas as condições adequadas para o seu estabelecimento e crescimento. Na Caverna de Pedra Pintada, no município de Monte Alegre, estado do Pará, a paleontóloga Anna C. Roosevelt constatou a presença dos primeiros paleoíndios há cerca de 11.200 anos. Esses paleoíndios viviam da coleta de plantas nativas e da pesca, e chegaram a deixar pinturas nas cavernas. De acordo com o artigo de Thomas et al., provavelmente os frutos representados nessas pinturas rupestres foram colhidos de árvores de castanheira que alcançaram a área por expansão natural, a partir de um ou mais refúgios menores, provavelmente localizados nas proximidades do delta do rio Amazonas. Concluem o artigo com excelentes e oportunas recomendações para

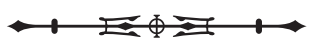


melhorar a conservação, uso e manejo da espécie, tanto dentro quanto fora da sua área de distribuição natural. Entre essas ótimas recomendações, destaco:

I. Projeções climáticas futuras preveem aumento ou adequação estável do habitat em diversas áreas onde a castanheira atualmente não cresce, tais como as áreas da costa atlântica colombiana do Pacífico, as Guianas, a região central da Bolívia e o sudeste do Brasil. Isso oferece oportunidades para começar a estabelecer a castanha-dobrasil nessas áreas agora, não só com a perspectiva de melhorar o estado de conservação da espécie no futuro, mas, provavelmente o mais importante, também para criar fontes adicionais de renda para as comunidades locais;

II. Não só as jovens castanheiras crescem muito rápido, como também rebrotam após o corte. Experiências no Brasil têm mostrado que monoculturas estabelecidas em altas densidades iniciais de plantio ( 1.000 árvores/ha) são permitidas para ciclos de corte de apenas quatro anos. Devido à rebrota vigorosa das árvores jovens, vários ciclos de corte podem ser possíveis. A madeira colhida de tais plantações pode ser comercializada em nichos de mercado, como na indústria do parquet;

III. A comercialização de madeira de castanheira-do-brasil deve, no entanto, não interferir na proibição legal de exploração madeireira da árvore em florestas naturais na Bolívia, no Brasil e no Peru. Diferentes abordagens podem ser usadas para controlar a exploração ilegal de madeira de castanheira-do-brasil. Uma medida seria permitir que apenas as toras de pequeno diâmetro possam ser comercializadas. Tais registros originários de plantações de curta rotação seriam, provavelmente, muito mais baratos em comparação a registros semelhantes, colhidos a partir de povoamentos naturais, o que tiraria o incentivo econômico necessário à exploração ilegal. Um mecanismo de controle, possivelmente, mais efetivo seria o uso combinado de marcadores genéticos e de isótopos, uma metodologia a ser testada atualmente pela rede global de monitoramento de madeira;

IV. A distribuição atual de castanheira-do-brasil em todo o continente sul-americano tem sido largamente influenciada por seres humanos desde a sua chegada à bacia do Amazonas, e não há nenhuma razão para que isso precise mudar no futuro. De fato, a evidência crescente sugere que o estabelecimento e o crescimento da castanheira-do-brasil podem ser promovidos por perturbação humana em pequena escala, como a agricultura de coivara; em escala intensa, como as áreas de mineração sob restauração; e em áreas de tensão ecológica, como a transição entre o cerrado (vegetação de savana tropical) e a Amazônia. Este comportamento poderia sugerir que a espécie tem certo grau de plasticidade e que algumas procedências podem mostrar maior tolerância à seca do que outras;

V. Por fim, os autores afirmam que atualmente uma proporção significativa das florestas com os castanhais mais produtivos já desfruta de certo status de proteção: no Brasil, por meio do sistema de reservas extrativistas; no Peru, por meio de concessões de castanha; e na Bolívia, por meio de participação da comunidade com relação às florestas de castanha. Um fato muito interessante para aqueles castanhais que, no Brasil, estão localizados em unidades de conservação de uso sustentável talvez seja a adaptação de uma legislação semelhante à do Peru e da Bolívia, para atender às populações tradicionais e agroextrativistas da região.

No segundo artigo, Homma e colaboradores descrevem a trajetória da castanha-do-pará como produto obtido essencialmente da coleta e do início da domesticação pelas comunidades indígenas pré-colombianas. Demonstram que, a despeito de ser um produto conhecido nos mercados interno e externo, a castanheira foi sendo vítima das políticas públicas que eram seguidamente implantadas na Amazônia. Recordam que os imigrantes japoneses que se instalaram no Pará, em Tomé-Açu (1929), e no Amazonas, em Parintins (1931), foram os primeiros a tentarem o plantio de castanheiras em sistemas agroflorestais (SAF), considerados a forma mais apropriada para garantir a sua viabilidade econômica.

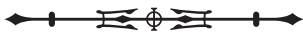


Observaram que, na década de 1980, com o desenvolvimento das técnicas de formação de mudas e de enxertia pela EMBRAPA, os plantios em grandes áreas apresentaram dificuldades com relação à questão da viabilidade econômica. A despeito da imagem extrativa e de não existirem estatísticas, estimaram que pelo menos $2 \%$ da produção de castanha-dopará são provenientes de plantios agrícolas. A longo prazo, o aumento da participação da castanha proveniente de plantios, tanto de pequenos como de médios e grandes produtores, é esperado. Alertam que, por ser uma planta totalmente dependente de polinização por insetos, a viabilidade de seus plantios depende da existência de reservas de vegetação secundária ou de floresta nas vizinhanças, para garantir a sobrevivência dos polinizadores durante todo o ano. Concluem que os desafios que se apresentam para o futuro são a recuperação da hegemonia brasileira, perdida para a Bolívia, as mudanças no processo de comercialização e as dificuldades para se transformar a castanheira em uma planta de cultivo.

Na microrregião do Médio Amazonas paraense, que abrange sete municípios do estado do Pará, foram desenvolvidos três estudos. Dois artigos analisam a dinâmica do crescimento de castanheira na região de Porto Trombetas, no município de Oriximiná: Salomão et al. trabalharam em áreas de mineração submetidas à restauração florestal e Scoles et al. em áreas quilombolas. O outro artigo foi desenvolvido por Cunha, que objetivou compreender a relação entre capital social e o acesso a recursos naturais e a mercados por comunidades quilombolas de Oriximiná.

De acordo com Salomão et al., a restauração de ecossistemas florestais tropicais sustentáveis em áreas de mineração é um desafio formidável, que exige a integração de técnicas de recuperação comprovadas e estratégias de reflorestamento apropriadas às condições específicas do local, incluindo os padrões de biodiversidade da paisagem. Restauradores que trabalham na maioria dos ambientes tropicais geralmente são prejudicados pela falta de informações básicas sobre a grande variedade de espécies de árvores nativas que caracterizam as florestas pré-perturbação, bem como insuficiente compreensão da ecologia da perturbação e recuperação natural para projetar programas eficazes de recuperação. $\bigcirc$ estudo analisou o crescimento em diâmetro e altura de árvores de castanheira para um período de 30 anos, na Floresta Nacional (FLONA) de Saracá-Taquera, onde a Mineração Rio do Norte promove a lavra da bauxita a céu aberto desde 1979. O trabalho analisou se taxas de crescimento de castanheira poderiam ser afetadas nessas áreas perturbadas. Concluíram que o crescimento em diâmetro e altura é inferior. No entanto, informam que B. excelsa é uma espécie com muito potencial de crescimento para uso na restauração florestal de áreas mineradas.

Em plantações experimentais de castanheira situadas na FLONA de Saracá-Taquera, em uma área de uso dos moradores da comunidade quilombola de Tapagem, Scoles et al. avaliaram o desempenho e a sobrevivência da castanheira em três ambientes, sob diferentes condições de luz. De acordo com os autores, a singularidade da pesquisa reside na comparação de três tratamentos ambientais dependentes de luz, que são os principais locais onde ocorre a regeneração natural dessa espécie, e também no fato de as áreas experimentais não serem submetidas a controles artificiais para a produção das mudas de castanheira, o que as aproximaria melhor das condições ambientais em que as plantas se regeneram. O monitoramento, após seis anos de mensurações e observações, revelou um desempenho em crescimento e altura significativamente mais alto das mudas plantadas em áreas abertas (roçados de lavoura de mandioca) do que aquelas localizadas em áreas de alto (sub-bosque de castanhais) ou intermediário sombreamento (capoeiras jovens). $\bigcirc$ artigo corrobora vários outros estudos que afirmam que a castanheira tem altíssimo potencial silvicultural para programas de reflorestamento, recuperação de ambientes degradados e enriquecimento de capoeiras, desde que haja os devidos cuidados culturais para manter as mudas juvenis expostas à luz solar direta.

O estudo de Cunha objetivou entender as relações entre o capital social e o acesso aos recursos naturais e mercados, relacionados à cadeia de valor da castanha-do-pará, focando-se nas comunidades quilombolas de Oriximiná e 
nos mercados nos arredores de Óbidos. Dados socioeconômicos e ambientais foram coletados por meio de entrevistas com agroextrativistas e em nível comunitário. Custos de transação altos, especialmente custos de transporte, e estruturas organizacionais insuficientes ao longo da cadeia de valor da castanha foram identificados como os dois principais problemas. Apesar de o preço da castanha ser limitado pelos mercados clássicos em funcionamento, como pelo suprimento e dinâmicas de demanda, a assimetria de informação e as relações de poder desequilibradas podem levar aos baixos preços pagos pelos compradores industriais aos compradores locais, as quais refletem o baixo retorno econômico que os agroextrativistas recebem pelo que coletam juntos. A conclusão do estudo é a de que sistemas de confiança são pilares-chave para construir capital social entre atores envolvidos na coleta e na comercialização da castanha-do-pará, bem como para estes membros da cadeia de valor promoverem a integração equitativa do mercado agroextrativista marginalizado.

A estrutura de uma população manejada de castanheira na FLONA de Caxiuanã, situada nos municípios de Melgaço e Portel, no Pará, foi analisada por Souza et al. Os indivíduos de castanheiras foram agrupados em três classes: regeneração natural, jovens e adultos. Como principais resultados, destacaram que a densidade de indivíduos jovens e adultos foi semelhante e muito alta para os padrões encontrados, e que mais da metade dos indivíduos da amostra pertencia aos grupos de regeneração natural e de jovens, indicando, segundo os autores, que a espécie se beneficia de áreas com perturbações antrópicas. Os autores concluem o estudo informando que a característica da expressiva quantidade de indivíduos bifurcados em Caxiuanã, em relação a outras áreas com aglomerados de castanheiras na Amazônia, pode estar relacionada ao estresse advindo do uso frequente de fogo para limpeza do sub-bosque e implantação de roças, estimulando juvenis, sobretudo varetas e varas, a desenvolverem suas gemas laterais, dando início à formação de novos fustes.

A importância da dispersão dos frutos para o manejo e a conservação da castanheira foi analisada por Faustino et al. em um castanhal nativo no estado do Acre, objetivando obter informações que subsidiassem uma definição segura sobre a melhor época e o intervalo de coleta dos frutos em um castanhal nativo neste estado. Durante o período de dispersão, árvores foram monitoradas, tendo seus frutos contados e marcados de acordo com o tempo de queda deles, que ocorreu em picos. Observaram que, após pouco menos de dois meses do início da dispersão, praticamente todos os frutos já haviam caído. Os resultados deste estudo indicam que a coleta deve começar a partir da oitava semana após o início da dispersão, e apenas um retorno nas árvores deve ser realizado para a coleta dos frutos remanescentes, proporcionando ganhos em termos de qualidade e maior eficiência na produtividade. No entanto, concluíram que uma análise de custo/benefício deve ser feita antes da tomada de decisão sobre a validade de fazer duas coletas na mesma árvore.

Em áreas de agricultura itinerante, no Amapá, Guedes et al. desenvolveram um método de manejo de castanheiras jovens, denominado 'castanha na roça', baseado em avaliações de áreas de agricultura migratória na Reserva Extrativista do rio Cajari (RESEX Cajari). Observaram que, no início da sucessão, as áreas apresentaram maior abundância de castanheira em comparação à floresta madura. A aplicação de um sistema de manejo para conservação das castanheiras nas capoeiras 'abandonadas' por iniciativa dos agroextrativistas e nas áreas de cultivo deve ser iniciada com o mapeamento e a quantificação dos exemplares desta espécie nessas áreas. É necessária densidade de pelo menos cinco castanheiras jovens, próximas de se tornarem produtivas, para que o agroextrativista tome a decisão de abandonar a capoeira e passe a considerá-la protegida. $\bigcirc$ estudo conclui que o reconhecimento de que a agricultura itinerante e o extrativismo são atividades complementares é essencial para a sustentabilidade da coleta de castanha, que pode ser garantida pelas novas castanheiras que surgem nas roças, e durante o desenvolvimento das capoeiras no período de pousio.

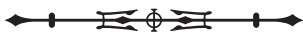


Tonini et al. analisaram a fenologia e a estrutura populacional de B. excelsa em castanhais nativos de Roraima, caracterizando as comunidades extrativistas e o sistema de extração praticado nesta região. Observaram que a extração de castanha-do-brasil apresenta significativo retorno financeiro para as famílias de ribeirinhos e indígenas de baixa renda, e que o extrativismo é praticado com baixa organização social, pouco apoio governamental e sem nenhum controle sobre os processos que podem levar à contaminação das castanhas por aflatoxinas, tanto na secagem como no armazenamento dos frutos. Concluíram que a abundância e a produtividade dos castanhais estudados no sul de Roraima estão dentro do esperado para a Amazônia, com algumas flutuações, e que naquela região a espécie floresce predominantemente na estação seca, tendo duração de cinco a seis meses; a dispersão dos frutos ocorre durante quatro a seis meses durante a estação chuvosa.

A cadeia produtiva de castanha-do-brasil no Acre foi analisada por Bayma et al. em uma nota de pesquisa. Segundo os autores, poucas cadeias produtivas apresentaram tantas mudanças em função de uma sequência de políticas públicas direcionadas ao setor, aliadas à estruturação de uma cooperativa central de produtores extrativistas. Apesar de toda essa mudança, especialmente no aumento da capacidade industrial para processamento da castanha-do-brasil, o Estado ainda necessita melhorar sua capacidade de beneficiamento da castanha-do-brasil, visando a uma política de maior agregação de valor que contribua para o fortalecimento e a sustentabilidade desta cadeia produtiva. Concluem informando que os produtores precisam ser melhor empoderados no elo produtivo desta cadeia, com políticas de preço diferenciado para castanha oriunda de boas práticas, considerando que este produto apresenta aproveitamento superior ao convencional (em torno de 15\%) dentro da indústria.

Finalmente, não se pode deixar de registrar textualmente algumas observações coletadas durante anos pelo pesquisador José Edmar Urano de Carvalho (comunicação pessoal, 19 de junho de 2013):

Nas últimas décadas, a produção brasileira de castanha-do-brasil vem decrescendo, tendo o país perdido a posição de maior produtor mundial, desde 2000, para a Bolívia. Como praticamente não existe a possibilidade de aumentar a produção pelo extrativismo, haja vista que todos os castanhais da Amazônia brasileira já estão sobre-explorados, a única alternativa é que a castanheira passe a ser cultivada mais intensamente, de tal forma que haja reversão parcial ou total do extrativismo para o cultivo. Essa Lecythidaceae já era cultivada empiricamente pelas populações indígenas, prova disso é que, quando os primeiros colonizadores europeus entraram nas terras amazônicas, a espécie já se encontrava em estado de domesticação incipiente. A propagação da castanheira pode ser efetuada por via sexuada (sementes) ou assexuada, especialmente por enxertia, pelos métodos de borbulhia em placa e garfagem no topo em fenda cheia. Na propagação assexuada, para se obter elevadas porcentagens de germinação, em tempo inferior a seis meses, é imprescindível que se efetue a remoção do tegumento, operação esta que requer habilidade. As sementes de castanha-do-brasil apresentam comportamento recalcitrante no armazenamento, ou seja, não suportam dessecamento, o que implica não poderem ser conservadas pelos métodos convencionais de armazenamento. Além dessa característica, apresentam sensibilidade a baixas temperaturas. A propagação por enxertia, além de reproduzir integralmente as características da planta-mãe, tem, ainda, como vantagem adicional o fato de reduzir substancialmente o tempo requerido para que as plantas entrem em fase reprodutiva. Enquanto castanheiras propagadas por sementes comumente só iniciam a produção de frutos entre oito e doze anos após o plantio, plantas propagadas por enxertia começam a produzir os primeiros frutos quatro anos após o plantio, embora produtividades comerciais só sejam atingidas após dez anos. A castanheira é espécie geneticamente autoincompatível e apresenta síndrome de polinização melitófila, sendo suas flores polinizadas por abelhas grandes, predominantemente dos gêneros Xylocopa, Centris e Epicharis. O espaçamento indicado para o plantio de castanheiras enxertadas em monocultivo é de $10 \times 10 \mathrm{~m}$. Em sistemas agroflorestais, deve ser bem mais aberto, não menos que 25 $\times 25 \mathrm{~m}$, em particular quando a espécie for utilizada para o sombreamento definitivo de plantas como o cacaueiro e o cupuaçuzeiro. A ocorrência de pragas e doenças é diminuta em pomares de castanheiras. Presentemente, a grande ameaça é representada pela lagarta da castanheira-do-brasil (Lusura latrix Stoll), constatada primeiramente atacando castanheiras nativas em Pando, na Bolívia. A castanha-do-brasil é consumida predominantemente ao natural. Tem larga aplicação na indústria de confeitaria, sendo utilizada em chocolates e doces finos. Na culinária amazônica, tem múltiplas aplicações, sendo o leite retirado de suas amêndoas ingrediente importante na preparação de peixes. O óleo da castanha, nos últimos tempos vem sendo bastante utilizado pelas indústrias de cosméticos.

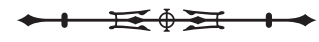


Acrescente-se, ainda, que a bela fotografia que ilustra a capa deste número especial, obtida por Antônio José Elias Amorim de Menezes (2014), é bem sugestiva e didática quanto ao que ocorreu com os castanhais nativos do Pará, sobretudo aqueles localizados no 'polígono do castanhais', no sul/sudeste do Pará. No processo de implantação da pecuária, a floresta primária foi derrubada, sendo mantidas as árvores de castanheiras por motivos de disposição legal. No entanto, quando a pastagem estava sendo formada, o uso do fogo era comumente empregado ano a ano. Sendo a castanheira uma espécie muito sensível ao fogo, após o terceiro ano das queimadas nas limpezas dos pastos, as árvores começavam a morrer, ficando como testemunhas aqueles troncos secos e sem copas bem evidenciados na foto. Persistindo essa forma de manejo, todas as belas castanheiras entraram em senescência, deixando a paisagem com um aspecto de 'paliteiro de cemitério de castanheiras'. O grande número de árvores vivas e mortas exibido na foto demonstra também a distribuição espacial homogênea da espécie que o caboclo chama de 'bola de castanha'.

Uma boa leitura!

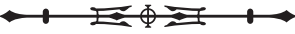

